\title{
Links between flood events in central Europe since AD 1500 and large-scale atmospheric circulation modes
}

\author{
J. Jacobeit, ${ }^{1}$ R. Glaser, ${ }^{2}$ J. Luterbacher, ${ }^{3,4}$ and H. Wanner ${ }^{3,4}$ \\ Received 10 October 2002; revised 13 December 2002; accepted 2 January 2003; published 22 February 2003.
}

[1] Based on documentary sources incidence variations of flood events can be reconstructed back to AD 1500 for several catchment areas in Central Europe. Links to atmospheric circulation modes, derived from recon-structed large-scale sea level pressure (SLP) grids for the last 500 years, have been identified on climatic time scales (monthly to seasonal). These relations are expressed in terms of several indices describing the particular importance of atmospheric circulation modes as a dynamical background for the varying incidence of flood events. During winter, the zonal circulation mode covers the largest part of these events, in relation to mode-frequency, however, other circulation modes become important during historical periods of increased flood frequency, e.g. modes characterised by Atlantic low and Russian high pressure centres. Different subtypes of this mode reached maxima in flood-association during different climatic periods of the past. INDEX TERMS: 3319 Meteorology and Atmospheric Dynamics: General circulation; 3309 Meteorology and Atmospheric Dynamics: Climatology (1620); 1821 Hydrology: Floods; 9335 Information Related to Geographic Region: Europe; KEYWORDS: Historical flood events, central Europe, circulation modes, circulation-floodrelationships. Citation: Jacobeit, J., R. Glaser, J. Luterbacher, and $\mathrm{H}$. Wanner, Links between flood events in central Europe since AD 1500 and large-scale atmospheric circulation modes, Geophys. Res. Lett., 30(4), 1172, doi:10.1029/2002GL016433, 2003.

\section{Introduction}

[2] Flood events are a major component among the various kinds of natural disasters contributing at least one third to the whole economic losses due to impacts of natural phenomena [Berz, 2000]. Besides several river and catchment area characteristics influencing flood dynamics [see Frei et al., 2000], the main control arises from climate variability [e.g., Shorthouse and Arnell, 1999]. In this context the primary importance of westerly flow types and of an enhanced NAO for Central European floods in the cold season has been forwarded [Bendix, 1997]. However, statistical analyses of extreme events should be based on very long-term data sets including periods of different climate characteristics [Knox, 2000]. Thus, there are strong indications that increased flood frequencies in Central Europe during parts of the 16th and 17th centuries occurred during

\footnotetext{
${ }^{1}$ Institute of Geography, University of Würzburg, Germany.

${ }^{2}$ Institute of Geography, University of Heidelberg, Germany.

${ }^{3}$ Institute of Geography, University of Berne, Switzerland.

${ }^{4}$ National Center of Competence in Research (NCCR) in Climate, Bern, Switzerland.
}

Copyright 2003 by the American Geophysical Union. 0094-8276/03/2002GL016433 periods with negative modes of the NAO. The present study will focus on the last 500 years based on recently available data (see next section) concerning both Central European flood events as well as reconstructed sea level pressure (SLP) grids for the North-Atlantic-European area.

[3] However, the aim of this study is not to perform detailed case studies or to analyse synoptic disturbances triggering anomalous river discharge. Investigations are rather linked to the concept of 'flood hydroclimatology' [Hirschboeck, 1988] which analyzes floods within the context of longer term varying climatic conditions and within a spatial framework of changing large-scale atmospheric circulation patterns. Dynamics at these scales provide the ultimative framework from which the more immediate causes of flooding are generated [Hirschboeck, 1988]. Thus, investigations will focus on major atmospheric circulation modes [Jacobeit et al., 2003] which may be derived from objectively reconstructed SLP grids for historical periods (typically with monthly to seasonal resolution). Their relation to flood events occurring on daily to weekly time-scales is an indirect one: different circulation modes are associated with different conditions for the development of flood-prone weather systems thus constituting a varying importance for flood events. Appropriate indices will be defined (section 3) to record various aspects of this importance which also includes favouring flood conditions in advance of the triggering event itself (e.g. by ice accumulation during winter). Hydrological extremes will thus be related to large-scale circulation dynamics and their long-term variability.

\section{Data}

[4] Historical flood events known from documentary sources [e.g. Brázdil et al., 1999] have been reconstructed back to AD 1500 for several catchment areas in Central Europe based on an impact approach, i.e. reported floods have been grouped into 3 intensity classes according to the severity of flood damages and their spatial extension [Glaser, 2001]. The following analyses exclude the less important class of lowest intensity and refer to the four most reliable time series - from the river Main and from central parts of rivers Rhine, Elbe and Weser - which have been integrated into one common flood series for Central Europe. Analyses will focus on winter time (December to February) being the most important flood season in this central part of Central Europe. Data from documentary sources extend until the end of the 18th century, for the subsequent instrumental period gauge observations and discharge measurements become available allowing to continue the historical flood series in terms of significantly above-average monthly maximum discharge [more than two standard deviations above the average maximum since 1850, see Sturm et al., 2001]. Since 


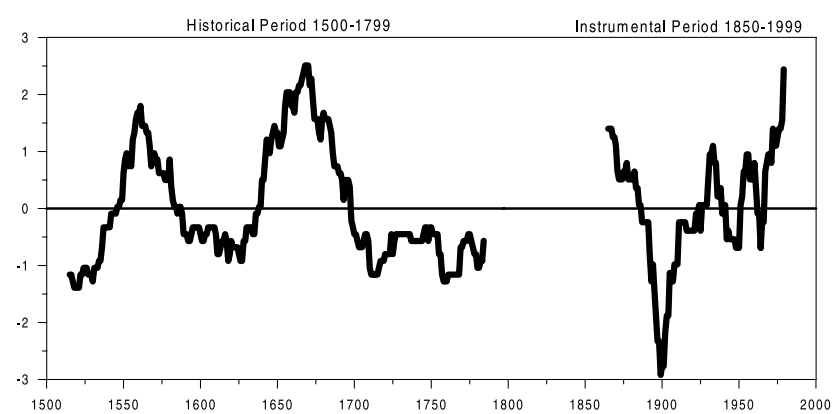

Figure 1. Normalized moving 31-year flood frequencies in Central Europe for the winter (DJF) season since 1500 based on four catchment areas (river Main and central parts of rivers Rhine, Weser, Elbe). The historical period is based on documentary data [Glaser, 2001], the instrumental period indicates frequencies of significantly above-average monthly maximum discharge since 1850 [Sturm et al., 2001]. Normalization is based on both periods in combination.

some of the instrumental data do not start before AD 1850 , the integrated time series is missing during the first half of the 19th century. Figure 1 shows running flood frequencies in Central Europe for moving 31-year time windows clearly indicating multi-decadal variations between increased and decreased flood incidence during both historical and instrumental periods of the past [Bendix, 1997].

[5] Atmospheric circulation analyses are based on gridded SLP data objectively reconstructed back to AD 1500 for the North-Atlantic-European area by Luterbacher et al. [2002] providing seasonal resolution until AD 1658, monthly resolution afterwards. Reconstruction skill has proved to be best during winter time thus supporting focus on this season, too. Atmospheric circulation modes used for this study have been adopted from Jacobeit et al. [2003] extending the temporal domain to the whole winter seasons since AD 1500. These dynamical modes are derived by a T-mode PCA and represented by SLP patterns (Figure 2) describing i) a large-scale zonal circulation $(\mathrm{Z})$, ii) a dipole configuration including a distinct Russian High pressure centre (RH), iii) a monopole configuration centered around the North Sea (M). The second mode (RH) has been subdivided into two subtypes (west and east) according to the zonal component over Central Europe (Figure 3) implying different air mass characteristics (Atlantic versus continental) in this region. Process-based explanations of these modes with respect to flood dynamics will be specified in conclusion of results based on particular indices (section 3) including the modes' time coefficients represented in a T-mode PCA by the principal components' loadings (correlation coefficients between original variables and resulting modes).

\section{Methods}

[6] The importance of circulation modes as a dynamical background for the varying incidence of flood events is assessed by three particular indices $(\mathrm{Q}, \mathrm{F}, \mathrm{C})$ :

a) $Q_{i}$ describes the flood quota of circulation mode $i$ by relating the flood events occurring during dominance of mode $i$ to the total amount of flood events. Dominance of mode $i$ is given by its time coefficient at time $t$ having the highest value among the time coefficients of all modes at time $\mathrm{t}$ - henceforth called the leading time coefficient $\mathrm{L}_{\mathrm{i}}(\mathrm{t})$. Instead of merely counting the number of flood events during dominance of mode $i$, the corresponding time coefficients of mode $i$ are summed up defining a frequency measure that includes a weighting factor according to the varying degree of dominance of mode $i$. Thus, we get

$\mathrm{Q}_{\mathrm{i}}={ }^{\mathrm{fl}} \mathrm{S}_{\mathrm{i}} / \mathrm{N}_{\mathrm{fl}}$ with ${ }^{\mathrm{fl}} \mathrm{S}_{\mathrm{i}}$ : sum of the leading time coefficients $\mathrm{L}_{\mathrm{i}}(\mathrm{t})$ of mode $\mathrm{i}$ for time units $\mathrm{t}$ with flood incidence; $\mathrm{N}_{\mathrm{fl}}$ : total number of flood events.

Calculations are not made with respect to the whole 500year period, but for moving 31-year time windows in order to record time-dependent variations in circulation-floodrelationships, too.

b) $\mathrm{F}_{\mathrm{i}}$ relates ${ }^{\mathrm{fl}} \mathrm{S}_{\mathrm{i}}$ to the size of the time windows:

$\mathrm{F}_{\mathrm{i}}={ }^{\mathrm{fl}} S_{i} / \mathrm{N}_{\mathrm{cp}}$ with $\mathrm{N}_{\mathrm{cp}}$ : total amount of time units $\mathrm{t}$ within each time window.

This index reflects different flood frequencies specified for each circulation mode. Since flood incidence has monthly resolution, $\mathrm{N}_{\mathrm{cp}}=93$ (31-year windows with 3 months) for the whole period since AD 1500.

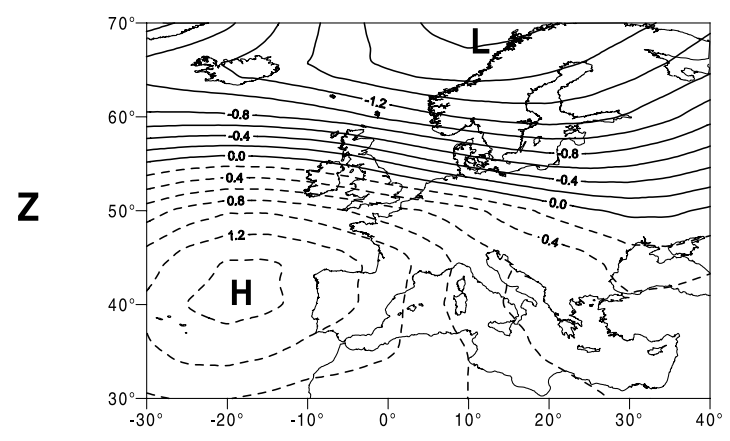

$46.3 \%$

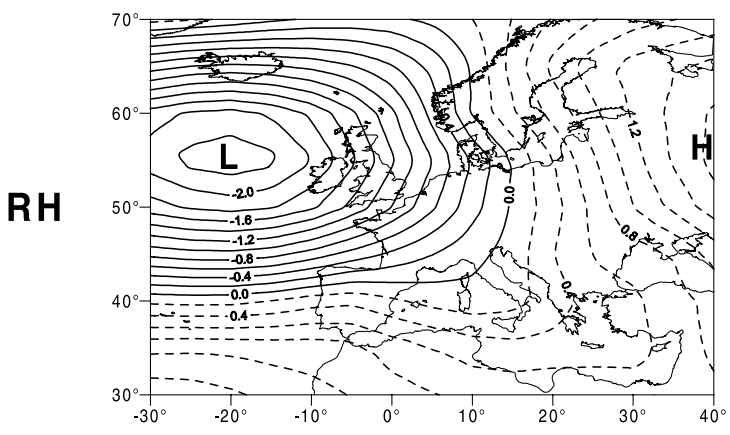

$31.9 \%$

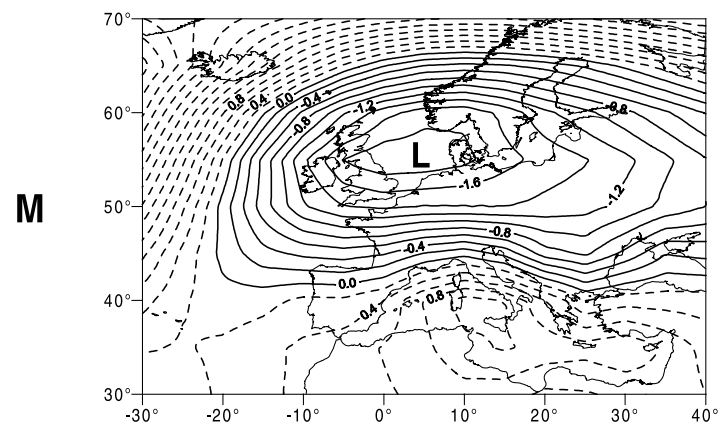

$12.8 \%$

Figure 2. Principal modes of winter (DJF) SLP 15001999 (abbreviations see text; percentages refer to variances accounted for by the corresponding modes). 


\section{RH Mode - Winter}
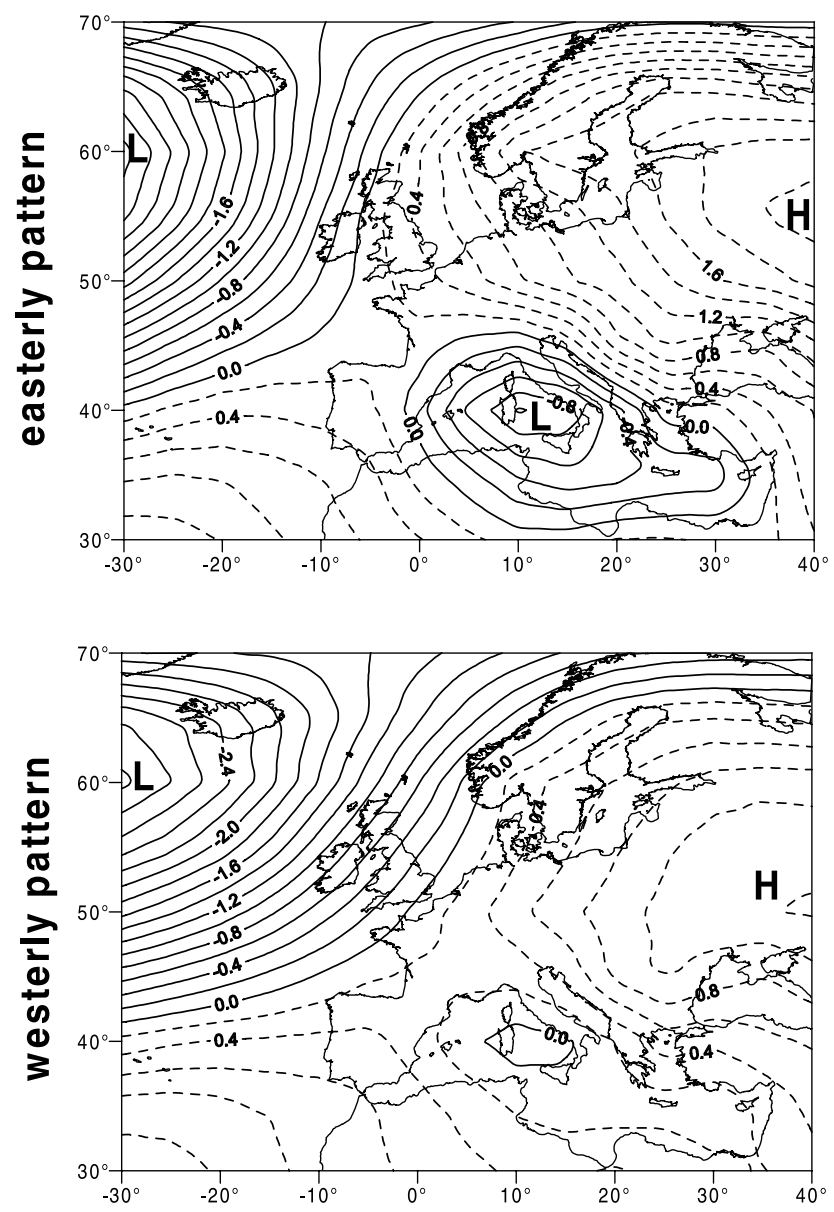

Figure 3. Subtype patterns of winter (DJF) SLP mode RH according to the zonal component over Central Europe. In this region subtypes imply an opposite air mass advection from Atlantic or continental areas, respectively.

c) $\mathrm{C}_{\mathrm{i}}$ relates ${ }^{\mathrm{fl}} \mathrm{S}_{\mathrm{i}}$ to the frequency of mode $\mathrm{i}$. If mode $\mathrm{i}$ is dominating at time $\mathrm{t}$ with $\mathrm{L}_{\mathrm{i}}(\mathrm{t})$ as leading time coefficient, this incidence is weighted by $\mathrm{L}_{\mathrm{i}}(\mathrm{t})$ considering again the varying degree of dominance of mode $i$. Thus, we get

$\mathrm{C}_{\mathrm{i}}={ }^{f l} S_{i} / \mathrm{S}_{\mathrm{i}}$ with $\mathrm{S}_{\mathrm{i}}$ : sum of all leading time coefficients $\mathrm{L}_{\mathrm{i}}(\mathrm{t})$ of mode $i$.

$\mathrm{C}_{\mathrm{i}}$ index gives evidence about the flood-association of circulation modes, i.e. how frequently the dominant occurrence of a particular mode is accompanied by flood events.

[7] Finally, the resulting Q,F,C time-series have been standardised across all circulation modes thus indicating directly above- and below-average flood-importance of these modes in terms of the three indices explained before.

\section{Results}

[8] Figure 4 shows the indices time series for the last 500 years (except of the first half of the 19th century where no appropriate flooding data were available). Gaps within the individual time series are due to lacks of maximum loadings for the corresponding circulation mode, i.e. it never occurred dominantly during the gap period, respectively. Index Q (Figure 4a) clearly reveals that most of the flood events were experienced during predominance of mode $\mathrm{Z}$, except of the earliest period in the 16th century when similar levels were reached by mode $\mathrm{RH}_{\text {west }}$. This mode declined afterwards in contrast to the increasing tendency for mode Z. Its Q-maximum during the 18th century, however, does not include an increased flood importance at this time as may be seen from Index F (Figure $4 b$ ) which drops down significantly just towards this century. The general background is the overall decrease in flood frequency after the peaks during the preceding centuries (Figure 1). These peaks as well as the modern ones are strongly reflected in F-maxima for mode $\mathrm{Z}$ whereas the other modes hardly exceed the mean level of Index F (Figure 4b).

[9] Completely different conditions appear with Index C (Figure $4 \mathrm{c}$ ): mode $\mathrm{Z}$ no longer has particular importance, instead there are several distinct maxima for other circulation modes: most prominent for mode $\mathrm{RH}_{\text {west }}$ during the 16 th century and for mode $\mathrm{RH}_{\text {east }}$ during the 17 th century. This means that increased fractions of these modes implied dynamics resulting in flood events whereas for mode $\mathrm{Z}$ such internal shifts did not occur or remained secondary. Flood impacts of circulation modes, however, may also operate quite indirectly as in the case of mode $\mathrm{RH}_{\text {east }}$ being responsible for pre-flooding accumulation or storage of extensive snow and ice volumes.

[10] Further evidence arises if flood events are weighted according to their spatial extension (i.e. a particular event is

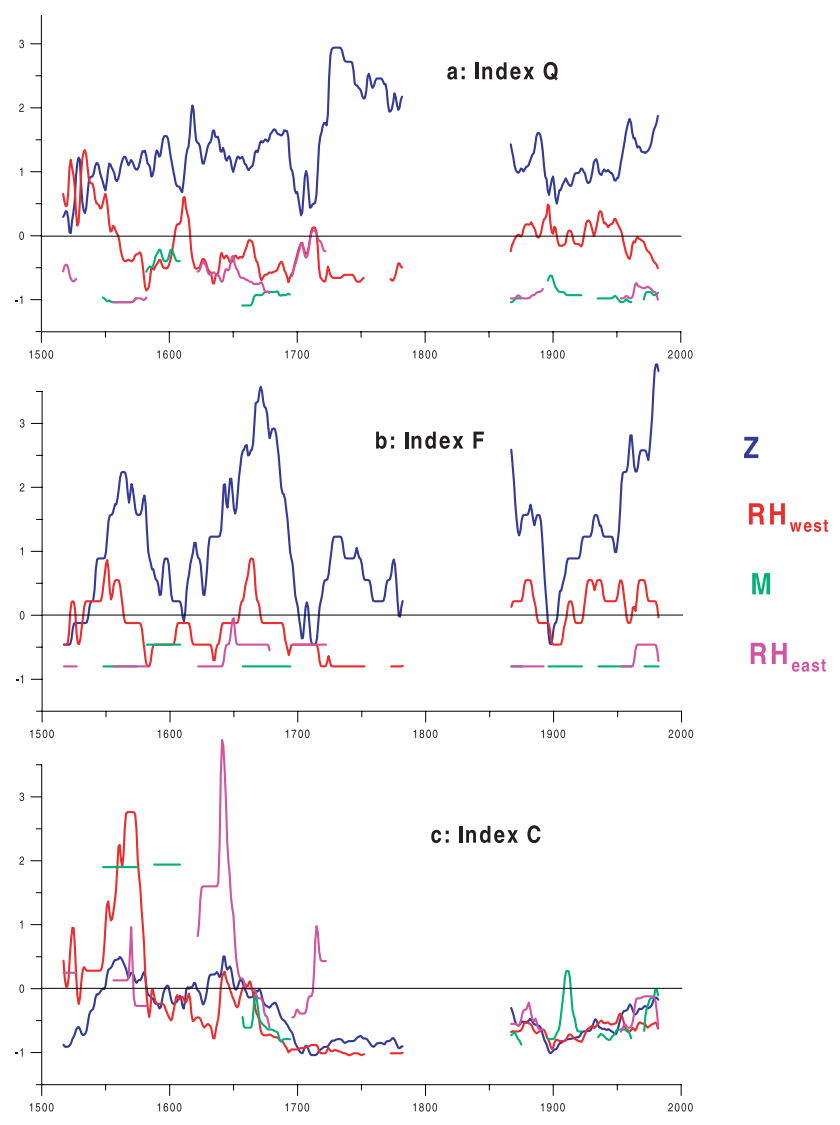

Figure 4. Normalized moving 31-year Q,F,C-Indices (see section 3 for definition) describing Central European floodimportance of large-scale circulation modes (symbols according to Figure 2) during the winter (DJF) season since AD 1500. 


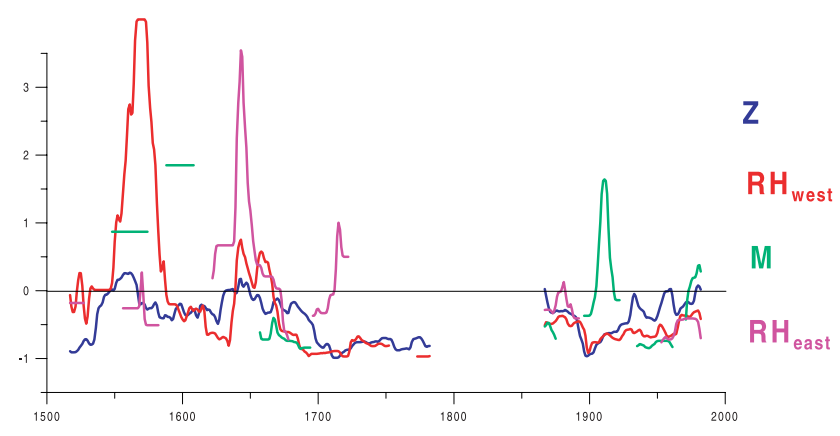

Figure 5. C-Index as in Figure 4c, but based on flood occurrence weighted with the number of affected catchment areas.

counted several times if it takes place within several catchment areas). With respect to the indices defined above (section 3), this means that ${ }^{\mathrm{fl}} \mathrm{S}_{\mathrm{i}}$ is weighted by the number of catchment areas affected by a flood event during the same time unit (varying between 1 and 4 in the present study). Figure 5 shows as an example the weighted results for Index $C$ thus referring to Figure $4 \mathrm{c}$ in comparison. The 16th century's maximum for mode $\mathrm{RH}_{\text {west }}$ is reproduced with even higher values. Mode $\mathrm{RH}_{\text {east }}$ decreases during the 16 th, but keeps its C-maximum of the 17 th century. Mode $\mathrm{Z}$ gets even lower values between 1500 and 1700. This implies that during the 16th century's period of increased flood frequency the occurrence of mode $\mathrm{RH}_{\text {west }}$ was linked with an enhanced risk of flood incidence, especially concerning widespread events affecting several catchment areas at the same time. Mode $\mathrm{RH}_{\text {east }}$, in contrast, only contributed by less widespread events in the 16th century and reached general importance not before the cold period of increased flood frequency in the 17 th century. Mode $\mathrm{Z}$, on the other hand, despite covering the largest number of flood events, only increased a little in its flood-association and in particular had reduced importance for widespread events. Remarkably, the modern period hardly indicates particular flood-associations except of a short C-maximum for mode $\mathrm{M}$ at the early 20th century (Figure 5).

\section{Conclusion}

[11] Links between Central European flood events and large-scale atmospheric circulation modes have been substantiated for the extended period of the last 500 years (winter season). The importance of the westerly type zonal circulation known from the last century [e.g., Caspary, 1995] could be confirmed only with respect to the quota of floods occurring during predominance of the large-scale zonal mode. On the other hand, in relation to modefrequency there is no particular association of floods with zonal circulation at monthly to seasonal time-scales, not even during the modern period. However, other circulation modes became increasingly associated with floods during historical periods of enhanced flood frequency: around the mid-sixteenth century the westerly subtype of the so-called Russian-High mode much more frequently implied flooding dynamics, with particular emphasis on widespread, nonsingular events in Central Europe. During this time in advance of a subsequent Little-Ice-Age-Type-Event cooling period [Wanner et al., 2000] the atmospheric circulation shifted towards more meridional patterns (mode RH), but still with rather easterly long-wave positions thus allowing strong disturbances from the central North Atlantic to enter the western parts of the European continent $\left(\mathrm{RH}_{\text {west }}\right)$. During the following cold period long-wave positions of mode $\mathrm{RH}$ moved increasingly towards the west (subtype $\mathrm{RH}_{\text {east }}$ ) concomitant with an initial decrease in flood frequency. Only around the mid-seventeenth century the enhanced ice accumulation linked with mode $\mathrm{RH}_{\text {east }}$ increased its floodassociation to a pronounced peak which fell within the second historical period of high flood frequency. The following decrease coincided with the so-called Late Maunder Minimum period which is known to have become progressively drier [Wanner et al., 1995, 2000].

[12] Thus, if studies are extended back into historical periods, a broader range of circulation modes becomes important in the context of varying flood events. Therefore, the assessment of flood dynamics at longer-term time scales must not be restricted to zonal mode and NAO considerations, but has to take into account the whole spectrum of variability in major circulation modes.

[13] Acknowledgments. This investigation was funded by the German Science Foundation (DFG) (contract number JA 831) by the Swiss National Science Foundation (contract number 11-52786-97) and by the Swiss National Center of Competence in Research (NCCR) in Climate.

\section{References}

Bendix, J., Natürliche und anthropogene Einflüsse auf den Hochwasserabfluss des Rheins, Erdkunde, 51, 292-308, 1997.

Berz, G., Flood disasters: Lessons from the past-Worries for the future, Kassel Reports of Hydraulic Engineering, 9, F1-F9, Herkules, Kassel, Ger., 2000.

Brázdil, R., et al., Flood events of selected European rivers in the sixteenth century, Clim. Change, 43, 239-285, 1999.

Caspary, H. J., Recent winter floods in Germany caused by changes in the atmospheric circulation across Europe, Phys. Chem. Earth, 20, 459-462, 1995.

Frei, C., et al., Climate dynamics and extreme precipitation and flood events in Central Europe, Integr. Assess., 1, 281-299, 2000.

Glaser, R., Klimageschichte Mitteleuropas: 1000 Jahre Wetter, Klima, Katastrophen, 227 pp., Wissenschaftliche Buchgesellschaft, Darmstadt, Ger., 2001.

Hirschboeck, K. K., Flood hydroclimatology, in Flood Geomorphology, edited by V. R. Baker, R. C. Kochel, and P. C. Patton, John Wiley, New York, 27-49, 1988.

Jacobeit, J., et al., Atmospheric circulation variability in the North-AtlanticEuropean area since the mid-seventeenth century, Clim. Dyn., 20, $10.1007 / \mathrm{s} 00382-002-0278-0,341-352,2003$.

Knox, J. C., Sensitivity of modern and Holocene floods to climate change, Quat. Sci. Rev., 19, 439-457, 2000.

Luterbacher, J., et al., Reconstruction of sea level pressure fields over the eastern north Atlantic and Europe back to 1500, Clim. Dyn., 18, 545$561,2002$.

Shorthouse, C., and N. Arnell, The effects of climatic variability on spatial characteristics of European river flows, Phys. Chem. Earth, Part B, 24, 7-13, 1999.

Sturm, K., et al., Hochwässer in Mitteleuropa seit 1500 und ihre Beziehung zur atmosphärischen Zirkulation, Petermanns Geographische Mitteilungen, 6, 14-23, 2001.

Wanner, H., et al., Wintertime European circulation patterns during the Late Maunder Minimum cooling period (1675-1704), Theor. Appl. Climatol., $51,167-175,1995$.

Wanner, H., et al., Interannual to centennial scale climate variability in the European Alps, Erdkunde, 54, 62-69, 2000.

R. Glaser, Institute of Geography, University of Heidelberg, Im Neuenheimer Feld 348, D-69120 Heidelberg, Germany.

J. Jacobeit, Institute of Geography, University of Wuerzburg, Am Hubland, D-97074 Wuerzburg, Germany. (jucundus.jacobeit@mail.uniwuerzburg.de)

J. Luterbacher and H. Wanner, Institute of Geography, University of Berne, Hallerstrasse 12, CH-3012 Bern, Switzerland. 